\title{
What is Ideal Proximal Resection Margin in Carcinoma Stomach
}

\author{
Mubarak Ahmad Shan, M.S., ' Syed Muzamil Andrabi, M.S., ${ }^{2}$ Mubashir Ahmad Shah, M.S., ${ }^{3}$ \\ Sameer Hassan Naqash M.S ${ }^{4}$ \\ 1. 2 Senior Residents, Department of General \& Minimal Invasive Surgery SKIMS \\ ${ }^{3}$ Additional Professor, Department of Upper Gl, Hepatobiliary \& Pancreatic Division \\ ${ }^{4}$ Professor \& Head Division of Upper Gl, Hepatobiliary \& Pancreatic Division.
}

\section{A B S T R A C T}

Objective: The goal of cancer surgery is to achieve clear margins, where the surgeon resects the tumor along with normal adjacent tissue and pathologist confirms the absence of cancer cells of the margin of this resected tissue. Complete resection with negative surgical margins along with lymph node dissection has been accepted as the only possible curative treatment for gastric cancer. Although there have been several studies on the sufficient length of margins that guarantees tumor-free resection and prevents local recurrences, definite consensus has not yet been reached, especially about the proximal resection margin (PRM).

Methods: The study was conducted in the Department of General Surgery, Sher I Kashmir Institute of Medical Sciences, Soura, Srinagar, Jammu and Kashmir, India between September 2011 and September 20013 and a total of 115 patients of Carcinoma stomach were included in the study. PRM of resected specimen was undertaken at $0.5 \mathrm{~cm}, 1 \mathrm{~cm}, 1.5 \mathrm{~cm}, 2 \mathrm{~cm}, 2.5 \mathrm{~cm}, 3 \mathrm{~cm}, 3.5 \mathrm{~cm}, 4 \mathrm{~cm}, 5 \mathrm{~cm}$ and $6 \mathrm{~cm}$. A resection margin was considered positive if permanent section examination revealed tumor tissue at the line of transection. The relation between infiltration of margins and various parameters of tumor like location, size, histological type and depth of invasion in to gastric wall was determined. The difference in the distribution and rate of margin infiltration was statistically evaluated, and a probability equal to or less than 0.05 was accepted as significant.

Results: Out of 115 patients of carcinoma stomach who underwent partial or total gastrectomy, proximal margin infiltration was seen in 5 patients (4.35\%). No infiltration of proximal margin was seen when the length of the resected margin was $>50 \mathrm{~mm}$. Margin infiltration was commonly found in tumors located at upper third, in diffuse histological type and with lymph node metastasis.

Conclusion: Since tumor infiltration at resection lines has been accepted as an adverse prognostic factor, negative resection margin are crucial components of curative surgery. Achieving a negative resection margin is the ultimate goal when determining the adequate length for PRM. In our study we found that a PRM of greater than $5 \mathrm{~cm}$ is ideal for having negative resection margin for all grades, sizes and T\& $\mathrm{N}$ stages of carcinoma stomach. JMS 2018; 21 (1):31-36

Key words: Proximal resection margin (PRM), Gastric malignancy, Gastrectomy

\section{INTRODUCTION}

Complete resection with negative surgical margins along with lymph node dissection has been accepted as the only possibly curative treatment for gastric cancer. Although there have been several studies on the sufficient length of margins that guarantees tumor-free resection and prevents local recurrences, ${ }^{[1,2]}$ definite consensus has not yet been reached, especially about the proximal resection margin (PRM).

Recurrence following curative surgery is a critical problem

\section{Correspondence}

Dr. Syed Muzamil Andrabi M.S.

Senior Resident, Department of General \&

Minimal Invasive Surgery SKIMS

Email: syedmiaz67@gmail.com for patients with gastric cancer, because most patients die within the first year after diagnosis of recurrence and the mean survival time has been reported to be only 8.7 months. ${ }^{[3]}$ Since any residual tumor cells at the resection lines may contribute to a recurrence, it is not unexpected that patients with positive margins have more recurrences than those with negative margins. ${ }^{[4,5]}$ In detailed analysis, however, there are several interesting issues. First, recurrences do not always develop in all patients whose resection margins have remaining cancer cells on microscopic examination. This phenomenon can be partly explained by the successful eradication of these cells by postoperative adjuvant therapies which are performed in some patients with positive margins. ${ }^{[6]}$ Furthermore, a few residual cancer cells could be eliminated by the patient's 
own immune system or poor blood supply at the resection margin. ${ }^{[7,8]}$ Another possibility is that tumor cells are involved only in diagnostic resection margins but not in the true surgical margins. Second, locoregional recurrence is not always the most common type of relapse in positivemargin patients. Locoregional is reported to be the most common recurrence pattern in negative-margin patients. ${ }^{[9,10]}$ These results are very interesting, because negative margins resulted in more locoregional recurrences but positive margins resulted in more distant recurrences. To what extent the grossly normal stomach tissue needs to be excised proximally is important, because it determines whether a total gastrectomy or distal gastrectomy should be performed.

\section{METHODS}

The study entitled "What is ideal proximal resection margin in carcinoma stomach" was conducted in the Department of General Surgery, Sher I Kashmir Institute of Medical Sciences, Soura, Srinagar, Jammu and Kashmir, India between September 2011 and September 20013 and a total of 115 patients of carcinoma stomach were included in the study. Detailed clinical history was taken and all patients were subjected to detailed clinical examination and appropriate investigations were done for exact size, site and stage of the disease like USG abdomen, EGD, CECT abdomen and chest and other baseline investigations. PET scan was not done in any patient for preoperative workup. Intraoperative frozen section (IFS) examination was not done due to non availability of the same. Patients were not assigned to any group intraoperatively and a macroscopic tumor free tissue was taken with the specimen which was postoperatively analyzed by the pathologist.

The type of surgery and operative findings were recorded in all patients. Measurement of proximal margins of specimen of carcinoma stomach were undertaken at $0.5 \mathrm{~cm}, 1 \mathrm{~cm}$, $1.5 \mathrm{~cm}, 2 \mathrm{~cm}, 2.5 \mathrm{~cm}, 3 \mathrm{~cm}, 3.5 \mathrm{~cm}, 4 \mathrm{~cm}, 5 \mathrm{~cm}$ and $6 \mathrm{~cm}$. A resection margin was considered positive if permanent section examination revealed tumor tissue at the line of transection. The relation between infiltration of margins of resection and various parameters of tumor like location of tumor, site of origin, gross appearance, size of the lesion, histological type and depth of invasion in to gastric wall was determined in 115 patients of proximal resection margins. The difference in the distribution and rate of margin infiltration was statistically evaluated, and a probability equal to or less than 0.05 was accepted as significant.

\section{Statistical analysis}

Statistical analysis was conducted using the SPSS version 16.0. Discrete clinicopathological variables were analyzed using the chi-squared test or Fisher's exact test.

\section{RESULTS}

A total of 115 patients of carcinoma stomach were included the study.

In our study it was seen that out of 5 patients with positive resection margin, 1 patient had a proximal resection margin of $1 \mathrm{~cm}$ only, 1 patient had a proximal resection margin of $2.5 \mathrm{~cm}, 2$ patients had proximal resection margin of less than $4 \mathrm{~cm}$ and only 1 patient with proximal resection margin of $4.5 \mathrm{~cm}$ had positive proximal resection margin. No patient with a proximal resection margin of greater than $5 \mathrm{~cm}$ had positive proximal resection margin.

The incidence of histological positive proximal margins in relation to the length of the grossly tumor free margin was analyzed. It is seen that no infiltration was found in 73 patients when the proximal margin was greater than $5 \mathrm{~cm}$. The overall incidence of infiltration was $4.35 \%$ in the resected specimens of proximal margin. $100 \%(1 / 1)$ incidence of infiltration was seen when the PRM length was $1-20 \mathrm{~mm}, 10 \%(1 / 10)$ incidence of infiltration was seen when the PRM length was 21-30mm, 25\% (2/8) incidence of infiltration was seen when the PRM length was $31-40 \mathrm{~mm}$ and $4.35 \%(1 / 23)$ incidence of infiltration was seen when the PRM length was $41-50 \mathrm{~mm}$. The mean distance between the margin of transection and gross periphery of the tumor was $2.5 \mathrm{~mm}$ in infiltrated margins.

Length of grossly tumor-free proximal edge and incidence of histological positive margin

\begin{tabular}{|c|c|c|c|}
\hline $\begin{array}{c}\text { Length of Margin } \\
(\mathbf{m m})\end{array}$ & \multirow{2}{*}{ No. of Patients } & \multicolumn{2}{|c|}{ Positive margin } \\
\cline { 3 - 4 } & & No & $\%$ \\
\hline $1-20$ & 1 & 1 & 100 \\
\hline $21-30$ & 10 & 1 & 10 \\
\hline $31-40$ & 8 & 2 & 25 \\
\hline $41-50$ & 23 & 1 & 4.35 \\
\hline$>50$ & 73 & 0 & 0 \\
\hline Total & 115 & 5 & 4.35 \\
\hline
\end{tabular}

Incidence and rate of infiltration of proximal margin according to the location, site, size, and gross appearance of the tumor

In our study we analyzed relationship between microscopic infiltration of resection margin with location, site, size and gross appearance of tumor. $10.7 \%$ (3/28) infiltration of resection margin was seen in tumors located in upper third 
of the stomach as compared with $3.03 \%(1 / 33)$ and $1.85 \%$ $(1 / 54)$ in tumors located in middle third and lower third of stomach respectively, there was no statistically significant correlation ( $p$ value 0.15 ). The incidence of microscopic infiltration of resection margins was correlated with respect to the size of the tumor, a significant correlation was seen (p value 0.038$)$. No infiltration of resection margin was seen when size of the tumor was $<30 \mathrm{~mm}, 5.17 \%(3 / 58)$ infiltration of resection margin was seen when the tumor size was $30-60 \mathrm{~mm}$ and $16.67 \%(2 / 12)$ infiltration of resection margin was seen when tumor size was $>60 \mathrm{~mm}$. Similarly relationship between gross appearance of tumor and involvement of resection margin was compared, but failed to show any significant correlation between the two. $5.38 \%(5 / 93)$ and $0 \%(0 / 22)$ infiltration of resection margin was seen in ulcerating and non ulcerating type of tumors respectively ( $\mathrm{p}$ value 0.58 ). With respect to the site of the tumor, $4.76 \%$ (2/42), $2.94 \%(1 / 34), 7.69 \%(1 / 13)$ and $3.85 \%(1 / 26)$ infiltration of margin was reported when tumor was sited at lesser curvature, lesser curve+ant-post wall, lesser curve-ant wall and all walls respectively. No significant statistical correlation seen between margin infiltration and site of the tumor ( $p$ value 0.91 ).

Table 2: Incidence and rate of infiltration of proximal margin according to the location, site, size, and gross appearance of the tumor

\begin{tabular}{|c|c|c|c|}
\hline & \multirow{2}{*}{$\begin{array}{l}\text { Total } \\
\text { No. }\end{array}$} & \multicolumn{2}{|c|}{ Margin positive } \\
\hline & & No. & $\%$ \\
\hline \multicolumn{4}{|l|}{ Location } \\
\hline Upper third & 28 & 3 & 10.7 \\
\hline Middle third & 33 & 1 & 3.03 \\
\hline Lower third & 54 & 1 & 1.85 \\
\hline Total & 115 & 5 & 4.35 \\
\hline \multicolumn{4}{|l|}{ Site } \\
\hline Lesser curvature & 42 & 2 & 4.76 \\
\hline $\begin{array}{l}\text { Lesser curvature }+ \\
\text { anterpost wall }\end{array}$ & 34 & 1 & 2.94 \\
\hline $\begin{array}{l}\text { Lesser curvature } \\
\text { anterior wall }\end{array}$ & 13 & 1 & 7.69 \\
\hline All walls & 26 & 1 & 3.85 \\
\hline Total & 115 & 5 & 4.35 \\
\hline \multicolumn{4}{|l|}{$\overline{\operatorname{Size}(\mathrm{mm})}$} \\
\hline$\leq \mathbf{3 0}$ & 45 & 0 & 0 \\
\hline$>30 \leq 60$ & 58 & 3 & 5.17 \\
\hline$>60$ & 12 & 2 & 16.67 \\
\hline Total & 115 & 5 & 4.35 \\
\hline \multicolumn{4}{|l|}{ Gross appearance } \\
\hline Ulcerating & 93 & 5 & 5.38 \\
\hline Non ulcerating & 22 & 0 & 0 \\
\hline Total & 115 & 5 & 4.35 \\
\hline
\end{tabular}

Incidence and rate of infiltration of proximal margin according to the degree of invasion of the gastric wall, histological type, and status of perigastric nodes

We also analyzed the relation between degree of invasion of gastric wall, histological type and perigastric lymph node status of the tumor with infiltration of margins. $0 \%(0 / 58)$ infiltration of resection margin was seen, when tumor was confined to mucosa, submucosa or muscularis, as compared to $8.77 \%$ (5/57) infiltration of resection margin was seen when tumor was confined to serosa and perigastric tissue, these results were statistically significant (P value 0.02 ). A significant correlation was seen between margin infiltration and lymph node status of the patient. 1.31\% (1/76) infiltration of margin was seen in lymph node negative patients, as compared to $10.26 \%$ (4/39) in lymph node positive patients (P value 0.04 ). No significant correlation was found between infiltration of margin and histology of the tumor (Pvalue 0.7).

Table 3: Incidence and rate of infiltration of proximal margin according to the degree of invasion of the gastric wall, histological type, and status of perigastric nodes

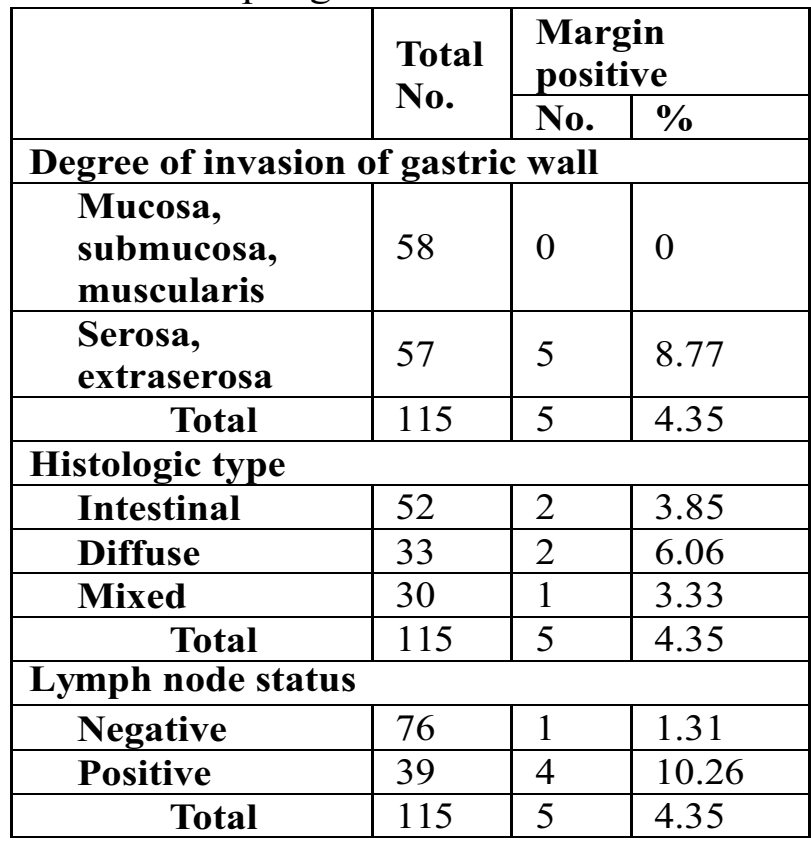

\section{DISCUSSION}

The goal of cancer surgery is to achieve clear margins; where the surgeon resects the tumor along with normal adjacent tissue and pathologist confirms the absence of cancer Cells of the margin of this resected tissue. Surgeon usually tries to cut the tissue to prevent situation where they 
cut in to cancerous cells, after this surgeon will send the removed tissue to lab for analysis. ${ }^{(11)}$ Many predictors of positive margins after curative resection of gastric cancer have been elucidated. Larger tumor size, higher $\mathrm{T}$ stage, higher $\mathrm{N}$ stage, higher overall stage, Borrmann type 4, diffuse histologic type, positive lymphatic vessel invasion, and upper tumor location were found to be associated with a higher probability of resection line infiltration by tumor cells. ${ }^{[5,12,13,14]}$

Because of the intramural spread of gastric cancer, a sufficient length of a resection margin has to be attained to ensure complete excision of the tumor. There has been debate on an adequate length of proximal resection margin (PRM) and its related issues. Although there is some discrepancy in the recommended values for PRM between authors, a PRM of more than $2-3 \mathrm{~cm}$ for early gastric cancer and $5-6 \mathrm{~cm}$ for advanced gastric cancer is thought to be acceptable. Once the margin is confirmed to be clear, however, the length of PRM measured in postoperative pathologic examination does not affect the patient's survival, even when it is shorter than the recommended values. Hence, the recommendations for PRM length should be applied only to intraoperative decision-making to prevent positive margins on the final pathology. Given that a negative resection margin is the ultimate goal of determining an adequate PRM, development and improvement of reliable methods to confirm a negative resection margin intraoperatively would minimize the extent of surgery and offer a better quality of life to more patients. In the same context, special attention has to be paid to patients who have advanced stage or diffuse-type gastric cancer, because they are more likely to have a positive margin. Therefore, a wider excision with IFS examination of the resection margin is necessary. Despite all the attempts to avoid positive margins, there is still a certain rate of positive-margin cases. Since the negative impact of a positive margin on prognosis is mostly obvious in low $\mathrm{N}$ stage patients, aggressive further management, such as extensive re-operation, is required for these patients. In conclusion, every possible preoperative and intraoperative evaluation should be thoroughly carried out to identify in advance the patients with a high risk of having positive margins; these patients need careful management with a wider excision or an IFS examination to confirm a negative margin during surgery. ${ }^{[15]]}$

Curative resection for gastric cancer could be considered to be an ideal surgical method that shows not only high survival rate after surgery but also causes less complications, and maintenance of a high quality of life. In addition, on account of diagnostic methods and physical examination being performed widely, gastric cancer is diagnosed early in many cases, and survival rate was improved owing to individualized combination therapy, and thus the safety associated with surgery or quality of life after surgery are considered inevitably. From such a point of view, if long-term survival rate is not different, surgeries that allow maintaining good quality of life or inducing less post-surgical complications should be considered first. In surgery for gastric cancer, the basic point in curative surgery is that microscopic residual cancer cells should not be detected in the resection margin, which has been well known as a factor exerting effects on post-surgical prognoses. Nonetheless, the gold standard that shows the distance from tumor margin to the resection margin has not been established. ${ }^{[16]}$

In this study we evaluated 115 gastric cancer patients, who underwent gastric resection or total gastrectomy. In our study, the distance from tumor margin to proximal resection margin was sub divided at $1 \mathrm{~cm}, 1.5 \mathrm{~cm}, 2 \mathrm{~cm}, 2.5 \mathrm{~cm}, 3 \mathrm{~cm}$, $3.5 \mathrm{~cm}, 4 \mathrm{~cm}, 4.5 \mathrm{~cm}$ and $5 \mathrm{~cm}$. This study provides surgeon with some basic guidelines, on a statistical bases, concerning the proximal extent of gastric resection for cancer.

In this study we evaluated correlation between margin infiltration and various parameters of the tumor like location, site, size, gross appearance, histological type, lymph node status, and depth of invasion. Proximal margin infiltration was seen in $4.35 \%$ of patients $(5 / 115)$. Which is consistent with the studies carried by Cascinu S, et al ${ }^{[5]}$ and $\mathrm{Kim} \mathrm{SH}$, et al ${ }^{[13]}$ ( prevalence of positive margins in these studies has been reported to be $0.8-20 \%$ ). Out of 5 patients with positive resection margin , 1 patient had a proximal resection margin of $1 \mathrm{~cm}$ only, 1 patients had a proximal resection margin of $2.5 \mathrm{~cm}, 2$ patients had proximal resection margin of less than $4 \mathrm{~cm}$ and only 1 patient with proximal resection margin of $4.5 \mathrm{~cm}$ had positive proximal resection margin. No patient with a proximal resection margin of equal or greater than $5 \mathrm{~cm}$ had positive proximal resection margin which is consistent with the results shown by Doosup Shin and Sung-Soo Park, ${ }^{[15]}$ according to them a proximal margin of $5-6 \mathrm{~cm}$ for advanced gastric carcinoma is thought to be acceptable. No infiltration of the margin was 
seen in 73 patients when the length of the proximal margin was equal or $>5 \mathrm{~cm}, 18.18 \%$ and $9.68 \%$ infiltration of proximal margin was seen respectively when the length of the proximal margin was $1-30 \mathrm{~mm}$ and $30-50 \mathrm{~mm}$, which is inconsistent with the results shown by Fedrico Bozzeti et al, ${ }^{[17]}$ possible explaination for this may be small sample size in our study. In our study out of 58 patients who had mucosa, submucosa or muscularis involvement, none of the patients had proximal margin infiltration. In all of these 58 patients, length of the proximal resection margin attained during procedure was $>5 \mathrm{~cm}$, while as $8.77 \%(5 / 57)$ infiltration of proximal margin was reported in patients of serosal or extraserosal involvement of the tumor, these results are consistent with the results shown by Ito $\mathrm{H}$ et al. ${ }^{(18)}$ In this study we also evaluated correlation between margin infiltration with the histology of the tumor and status of perigastric lymph nodes. Out of 5 positive proximal resection margins, 2 patients (2/ 52) had intestinal type of histology, 2 patients (2/33) had diffuse type of histology and only 1 patient (1/30) with mixed variety of histology had positive proximal resection margin, which is consistent with the results shown by $\mathrm{Kim} \mathrm{SH}$, et al. ${ }^{(13)} 1.31 \%$ (1/76) infiltration of margin was reported in lymph node negative patients as compared to $10.26 \%(4 / 39)$ in patients with lymph node metastasis, consistent with the studies carried by $\mathrm{H}$ Clark $\mathrm{CJ}$, et al. ${ }^{[19]}$ In this study we also evaluated correlation between margin infiltration and other parameters like location of tumor, site of the tumor, size of the tumor and gross appearance of the tumor. In this study we observed that out of 28 patients with the lesion located at upper third of stomach, 3 had positive proximal resection margins, 1 out of 33 in lesions located at middle third and 1 out of 54 patients when tumor was located at lower third of stomach had positive proximal resection margin, consistent with the results shown by Cascinu $\mathrm{S}$ et al. ${ }^{[5]}$ Out of 45 patients with the tumor size less than $3 \mathrm{~cm}$, none of the patient had positive proximal resection margin. 3 out of 58 patients had positive proximal resection margin when tumor size was between $3-6 \mathrm{~cm}$ and 2 patients out of $12 \mathrm{had}$ positive proximal resection margin when tumor size was $>6 \mathrm{~cm}$, which is consistent with the results shown by Wang $\mathrm{SY}$, et al. ${ }^{[12]}$ When infiltration of proximal resection margin involvement was correlated with site of the lesion, 2 out of 42 patients had proximal margin involvement in tumors sited at lesser curvature, 1 out of 34 patients had margin involvement when tumor was confined to lesser curve as well as anterior an posterior gastric wall, 1 out of 13 patients had proximal margin involvement when tumor was sited at lesser curve and anterior wall of stomach and 1 patient out of 26 had positive resection margin when all the walls of stomach were involved by the tumor, consistent with the results shown by Fedrico Bozzetti et al. ${ }^{[17]}$ On gross appearance of the tumor, out of 93 patients of ulcerating type of lesions, 5 patients had proximal margin involvement and none of the patients with non ulcerating morphology had infiltration of the proximal margin, consistent with the results shown by Fedrico Bozzetti et al. ${ }^{[17]} 5$ patients who had proximal margin involvement were referred to the medical oncology department for adjuvant therapy.

\section{CONCLUSION}

Since tumor infiltration at resection lines has been accepted as an adverse prognostic factor, negative resection margins are crucial components of curative surgery. Achieving a negative resection margin is the ultimate goal when determining the adequate length for PRM. In our study we found that a PRM of greater than $5 \mathrm{~cm}$ is ideal for having negative resection margin for all grades, sizes and $\mathrm{T} \& \mathrm{~N}$ stages of carcinoma stomach.

\section{REFRENCES}

1. Papachristou DN, Fortner JG. Local recurrence of gastric adenocarcinomas after gastrectomy. J Surg Oncol 1981; 18: 47-53.

2. Kakeji Y, Korenaga D, Baba H, Watanabe A, Tsujitani S, Maehara Y, Sugimachi K. Surgical treatment of patients with gastric carcinoma and duodenal invasion. J Surg Oncol 1995;59:215-219.

3. Yoo $\mathrm{CH}$, Noh SH, Shin DW, Choi SH, Min JS. Recurrence following curative resection for gastric carcinoma. Br J Surg 2000; 87: 236-242.

4. Sun Z, Li DM, Wang ZN, Huang BJ, Xu Y, Li K, Xu HM.Prognostic significance of microscopic positive margins for gastric cancer patients with potentially curative resection.Ann Surg Oncol 2009; 16: 30283037.

5. Cascinu S, Giordani P, Catalano V, AgostinelliR,Catalano G. Resection-line involvement in gastric cancer patients undergoing curative resections: implications for clinical management. Jpn J Clin Oncol 1999; 29: 291-293 [PMID: 10418557].

6. Morgagni P, Garcea D, Marrelli D, de Manzoni G, NataliniG, Kurihara H, Marchet A, Vittimberga G, 
Saragoni L, Roviello F, Di Leo A, De Santis F, Panizza V, Nitti D. Does resection line involvement affect prognosis in early gastric cancer patients? An Italian multicentric study. World J Surg 2006; 30: 585-589.

7. Morgagni P, Garcea D, Marrelli D, De Manzoni G, Natalini G, Kurihara H, Marchet A, Saragoni L, Scarpi E, Pedrazzani C, Di Leo A, De Santis F, Panizzo $\mathrm{V}$, Nitti D, Roviello F. Resection line involvement after gastric cancer surgery: clinical outcome in nonsurgically retreated patients. World J Surg 2008; 32: 2661-2667.

8. Nagata T, Ichikawa D, Komatsu S, Inoue K, Shiozaki A,Fujiwara H, Okamoto K, Sakakura C, Otsuji E. Prognostic impact of microscopic positive margin in gastric cancer patients.J Surg Oncol 2011;104: 592597.

9. Roviello F, Marrelli D, de Manzoni G, Morgagni P, Di Leo A, Saragoni L, De Stefano A. Prospective study of peritoneal recurrence after curative surgery for gastric cancer. Br J Surg 2003; 90: 1113-1119.

10. D'Angelica M, Gonen M, Brennan MF, Turnbull AD, Bains M, Karpeh MS. Patterns of initial recurrence in completely resected gastric adenocarcinoma. Ann Surg 2004; 240: 808-816.

11. WWW. Breast cancer. Org/symptoms/ diagnosis/margins.JSP. Cached www.wellsphere.com/ rectal resection margin- 168(2597).

12. Wang SY, Yeh CN, Lee HL, Liu YY, Chao TC, Hwang TL, Jan YY, Chen MF. Clinical impact of positive surgical margin status on gastric cancer patients undergoing gastrectomy. Ann Surg Oncol 2009; 16: 2738-2743.
13. Kim SH, Karpeh MS, Klimstra DS, Leung D, Brennan MF. Effect of microscopic resection line disease on gastric cancer survival. J Gastrointest Surg 1999; 3: 24-33.

14. Cho BC, Jeung HC, Choi HJ, Rha SY, Hyung WJ, Cheong JH, Noh SH, Chung HC. Prognostic impact of resection margin involvement after extended (D2/D3) gastrectomy foradvanced gastric cancer: a 15-year experience at a single institute. J Surg Oncol 2007; 95 : 461-468.

15. Doosup Shin and Sung Soo Park. World Journal Gastrointestinal oncology, 2013 January 15; 5(1): 411.

16. Ji Hyun Lee and Yong Kim. What is optimal extent of Resection in middle third gastric cancer between total gastrectomy and subtotal gastrectomy. Department of Surgery, School of Medicine Ewha Womans University, Seoul, Korea.

17. Fedrico Bozzeti, MD, Giuliano Bonafanti, Rosaria Bufalino, velio Menotti, Silvio Persano et al, from the istituto Nazionale per lo Studio e la Cura dei Tumori, Milano Italy.

18. Ito H, Clancy TE, Osteen RT, Swanson RS, Bueno R, Sugarbaker DJ, Ashley SW, Zinner MJ, Whang EE. Adenocarcinoma of the gastric cardia: what is the optimal surgical approach? J Am Coll Surg 2004; 199: 880-886.

19. H, Clark CJ, Thirlby RC, Picozzi V, Schembre DB, Cummings FP, Lin E. Current problems in surgery: gastric cancer. Curr Probl Surg 2006; 43: 566 -+670. 